\title{
Potpourri of interesting scalp lesions
}

\author{
Hegde S. ${ }^{1}$, Samartha V. \\ ${ }^{1}$ Dr. Shreya Hegde, Assistant Professor, ${ }^{2}$ Dr. Vinitha Samartha, Assistant Professor; Both authors are affiliated with the \\ Department of Pathology, A.J. Institute of Medical Sciences and Research Centre, Mangaluru, Karnataka, India.
}

Corresponding Author: Dr. Vinitha Samartha, Assistant Professor; Department of Pathology, A.J. Institute of Medical Sciences and Research Centre, Mangaluru, Karnataka. India. E-mail: drshreyahegde@gmail.com

\begin{abstract}
Introduction: Painless soft tissue masses on the scalp are commonly encountered in clinical practice. The most likely diagnoses still remain as epidermoid cysts, sebaceous cysts and benign lipomas. The aim of this study is to exhibit the vast variety of scalp lesions, with emphasis on the metastatic scalp lesions. Materials and Methods: This was a retrospective study carried out in the Department of Pathology in a tertiary care hospital in coastal Karnataka, India. A total of 29 scalp lesions received during the period were included in the study. Paraffin blocks and slides along with case records were retrieved and studied. Results: Out of a total of 29 scalp lesions included in this study, the most common lesion was lipoma. The most interesting cases were the 5 cases of scalp lesions which were metastasis from visceral organs, the most common site being the thyroid. Conclusion: A wide histopathological range of lesions comprising of neoplastic and non-neoplastic lesions were found. The most common lesion in this study was lipoma, while the most interesting were metastatic scalp lesions.
\end{abstract}

Keywords: Cutaneous metastases, Lipoma, Scalp lesions

\section{Introduction}

A wide variety of scalp lesions are identified as palpable masses or as incidental findings on radiologic studies. They represent a challenge for clinicians and radiologists, with similar appearances on radiologic images that may lead to diagnostic mistakes.In contrast to the common belief that metastatic lesions are usually skin nodules or tumors that are distinct from primary skin lesions, it has been found that some metastases, particularly when they are a single lesion, can closely simulate a benign cyst, keratoacanthoma, basal cell carcinoma, or melanoma. Correct interpretation of a scalp mass may lead to reduced mortality and morbidity and may guide physicians toward the most appropriate management $[1,2]$.

The scalp extends from the external occipital protuberance to the supraorbital margin. Although the incidence of tumors arising on the scalp is increased compared to those occurring elsewhere on the skin, these neoplasms are fortunately predominantly benign. Cysts constitute over $50 \%$ of benign scalp tumors and primarily include trichilemmal, epidermoid and dermoid cysts. There are numerous other benign scalp tumors such as lipoma, fibroma, pilomatricoma (calcified cyst), seborrheic keratosis, nevi, hemangioma, warts and pseudolymphoma.

[3]

Manuscript received: $26^{\text {th }}$ October 2019

Reviewed: $8^{\text {th }}$ November 2019

Author Corrected: $16^{\text {th }}$ November 2019

Accepted for Publication: $22^{\text {nd }}$ November 2019
Cutaneous metastases of visceral malignancies are rare, but among these the scalp is a common site, probably due to its rich vascularity [4]. Clinically, scalp metastases may present as solitary or multiple nodules, papules or the most common finding being a bulging mass with nodule, with or without associated alopecia [5]. According to a study done by Hingway et al, the most probable cause for scalp metastases is malignancies from the head and neck region [4].

Cutaneous involvement may occur because of direct extension of the cancer or as a local/distant metastasis. The scalp is known to be a favoured location for distant metastasis, with approximately $5 \%$ of cases involving this site. Most cutaneous metastasis are diagnosed in patients prior to the finding of visceral malignancy. The interval between primary and metastatic diagnosis is more than 5 years in about $7 \%$ of cases. When skin metastases do occur, the chest and abdomen are the most common site, and they often present as ovoid or round nodules, firm and can be red, dark-red or black. They can also progress to ulceration. Unfortunately, half of the patients with cutaneous metastasis die within the first 6 months after the diagnosis $[6,7]$.

The aim of this study is to exhibit the vast variety of scalp lesions, with emphasis on the metastatic scalp lesions.

Pathology Update: Tropical Journal of Pathology \& Microbiology Available online at: www.medresearch.in 948 | P a g e 


\section{Materials and Methods}

Type of study: Retrospective study

Place of study: The study was carried out in a tertiary care hospital in a coastal region of Karnataka.

Duration of study: 2 years study from September 2016 to October 2018.

Sample collection: All specimens were received in $10 \%$ formalin and relevant clinical information was obtained. The specimen were then subjected to gross description and adequate sampling by appropriate tissue section. The microscopic features were then studied with routine Hematoxylin and Eosin stained sections. Special stains and Immunohistochemical studies were done as and when required.

Inclusion criteria: All specimen of scalp lesions of any age and sex having neoplastic (benign and malignant) etiology and have undergone histopathological examination following surgery was included in this study.

Exclusion criteria: All scalp lesions with non-neoplastic etiology were excluded from this study.

\section{Results}

A total of 29 cases of scalp lesions were included in this study, of which $24(83 \%)$ were benign and $5(17 \%)$ were malignant (Table 1).

Table-1: Distribution of lesions.

\begin{tabular}{|c|c|c|}
\hline Type of lesion & Number & Percentage \\
\hline Benign & 24 & $83 \%$ \\
\hline Malignant & 5 & $17 \%$ \\
\hline
\end{tabular}

All the 5 malignant lesions were metastasis from visceral organs, thyroid being the most common site of origin. Among the benign lesions, lipomas were the commonest tumours comprising 42\% (12 cases) of all lesions, followed by 5 ( $18 \%$ ) cases of dermoid cysts, $4(14 \%)$ cases of epidermoid cysts, and 1 (3\%) case each of pilomatricoma, fibroma and haemangioma (Table 2).

Table-2: Histomorphological patterns of lesions.

\begin{tabular}{|c|c|c|}
\hline Type of tumour & Number & Percentage \\
\hline Lipoma & 12 & $42 \%$ \\
\hline Dermoid cyst & 5 & $18 \%$ \\
\hline Epidermoid cyst & 4 & $14 \%$ \\
\hline Pilomatricoma & 1 & $3 \%$ \\
\hline Fibroma & 1 & $3 \%$ \\
\hline Haemangioma & 1 & $3 \%$ \\
\hline Metastasis & 5 & $17 \%$ \\
\hline
\end{tabular}

Thyroid was the most common primary tumour site with follicular carcinoma followed by equal distribution in lung, thymus and kidney with respective histological type being Keratinizing squamous cell carcinoma, Thymic carcinoma, Adenocarcinoma (Table 3).

Table-3: Site of primary tumour in cases of metastatic lesions.

\begin{tabular}{|c|c|c|}
\hline Primary tumour site & Histological type & Number \\
\hline Thyroid & Follicular carcinoma & 1 \\
\hline Lung & Keratinizing squamous cell carcinoma & 1 \\
\hline Thymus & Thymic carcinoma & 1 \\
\hline Kidney & Adenocarcinoma \\
\hline
\end{tabular}

Of the 29 cases, there were 5 cases of scalp metastases, each having a different site of origin. Case 1 was a 47 year old female patient, presenting with neck and scalp swelling of 6 months duration. An FNA of neck lesion was done and diagnosed as Bethesda Category IV - Follicular Carcinoma thyroid, which was then confirmed by histopathology. FNA of Scalp was diagnosed as Metastatic Follicular Carcinoma to the scalp (Figure 1). 


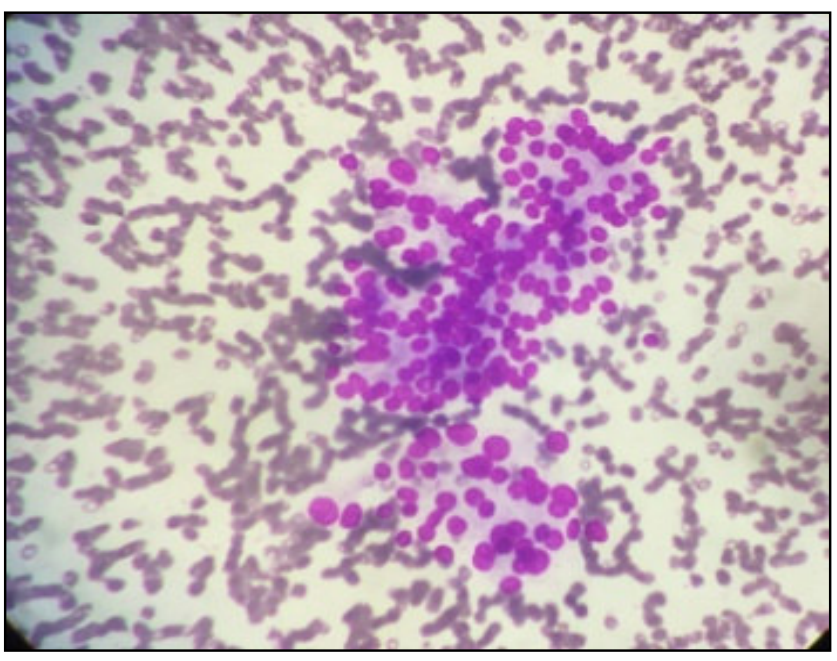

Fig-1: Metastasis from follicular carcinoma thyroid to scalp (Leishman's stain $x 45$ ).

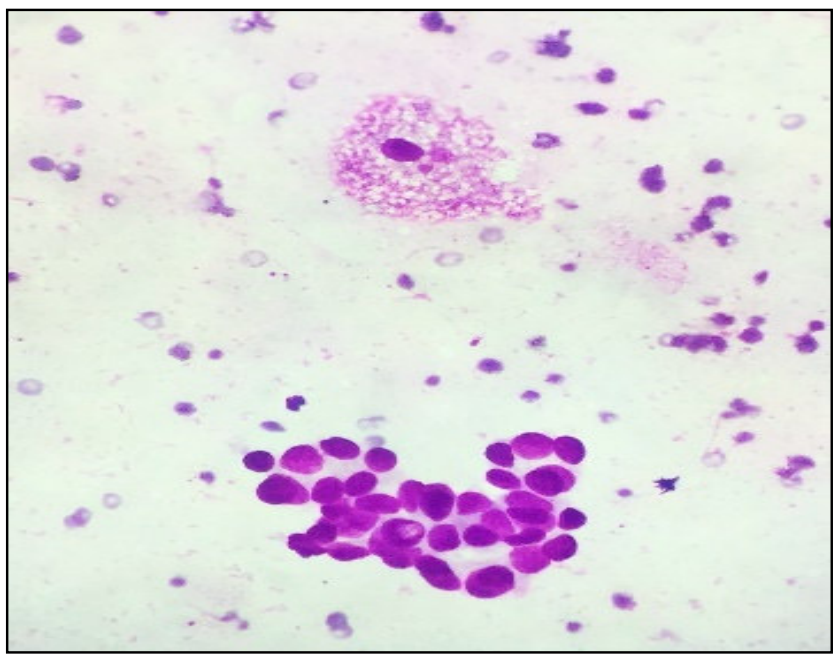

Fig-2: Predominant follicular pattern in metastasis from follicular carcinoma thyroid to scalp (Leishman's stain $\mathbf{x 4 5}$ ).

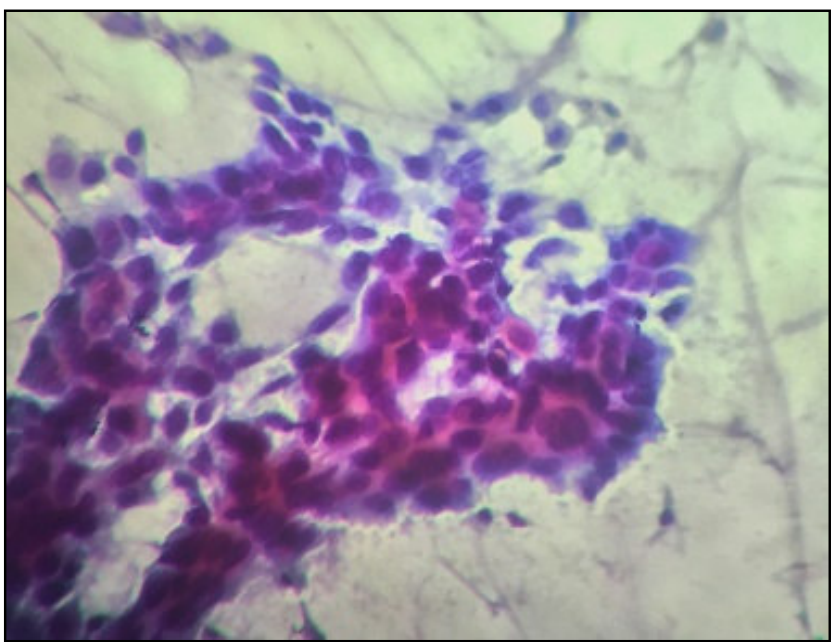

Fig-3: Metastasis from keratinizing squamous cell carcinoma of lung to scalp (Leishman's stain $\times 45$ ). 


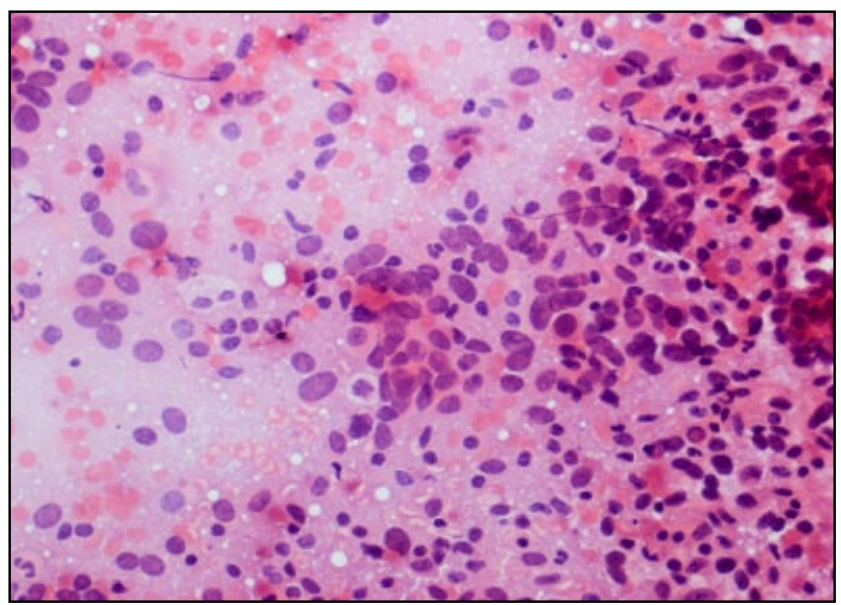

Fig-4: Metastasis from thymic carcinoma to scalp (Leishman's stain $x 45)$.

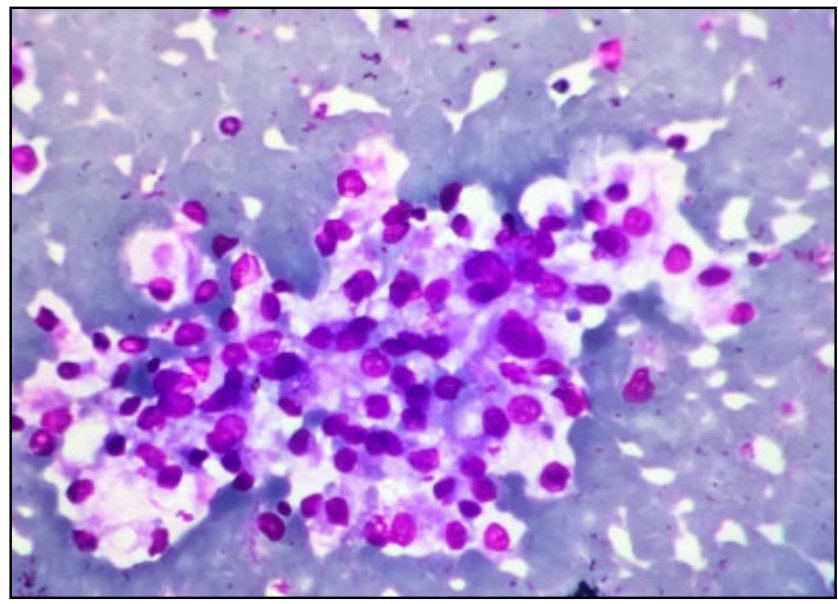

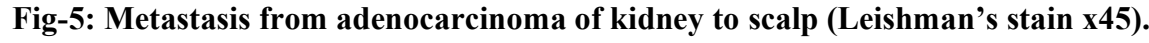

Case 2 was a 63 year old female patient, operated for follicular carcinoma thyroid and presented 8 months later with a scalp swelling. FNA of the scalp lesion revealed a Metastatic Follicular Carcinoma from thyroid to scalp. Case 3 was a 60 year old male patient, diagnosed and treated for keratinizing squamous cell carcinoma from the lung. 5 months later he presented with a swelling in the left cervical neck region and left side of the scalp. FNA was done and diagnosed as Metastatic Keratinizing Squamous Cell Carcinoma to left cervical lymph nodes and scalp.

Case 4 was a 42 year old male patient who presented with non resolving cough and chest pain. Radiological investigations revealed a thymic carcinoma which was surgically excised. 5 months later, he presented with scalp swelling which was diagnosed as Metastatic Carcinoma. In view of clinical history, metastasis from thymic carcinoma was suggested.

Case 5 was a 51 year old lady who presented with abdominal fullness and scalp swelling. Ultrasound abdomen revealed a complex lesion in the lower pole of the kidney. FNA of the scalp swelling was done and in view of the USG findings, cytologic diagnosis of metastatic adenocarcinoma from kidney was suggested, which was later confirmed by surgical excision and histopathology of the kidney lesion (Figure 2-5).

\section{Discussion}

Tumours of the scalp are characterized by an impressively broad and heterogeneousclinical spectrum. They frequently exhibit site-specific features distinguishing them from their counterparts elsewhere on the skin. Although mostly benign, diagnosis and treatment of these lesions may pose a significant challenge due to impaired visibility (and thus

delayed detection), anatomical circumstances, exposure to (exogenous) noxious agents, distinct histological features, as well as the often-advanced age of affected individuals. This is even more true for malignant tumours of the scalp, which are uncommon but associated with a poor prognosis[3]. 
The discovery of cutaneous metastasis may be the first indication of an underlying malignancy or recurrence in a patient with a known primary. Characteristic, although rare, locations of solitary cutaneous metastases are the scalp and the umbilicus [5]. Cutaneous metastases, although rare, must be among the differential diagnosis of skin lesions and that a diagnostic research based on these findings can be conducted [8].

Rasbach et al. and Damewood et al. reviewed post-mortem examinations of 2279 autopsy studies of patients who died from internal neoplasm; only 58 cases of skin metastasis $(2.5 \%)$ were identified. The majority of these lesions were located on the trunk and extremities. Breast $(69 \%)$, colon (9\%), melanoma (5\%), and ovary cancer (4\%) were identified as the primary tumors that typically metastasize to the skin. Breast cancer is the most common origin of cutaneous metastases in women and lung cancer is the most common origin in men.

Diffuse distribution of subcutaneous nodules suggests hematogenous rather than lymphatic spread. When skin metastases are identified, they usually represent widespread dissemination of the underlying malignancy. Skin metastases from endometrial adenocarcinoma are extremely rare. Fortunately, most cases are diagnosed at an early stage when surgery alone may be adequate for cure [9].

Gates et al reported an autopsy series of 2,298 carcinomas, with 58 skin metastases. Abrams et al found 44 cases of skin metastases in 1,000 autopsied cases of carcinoma. In a study by Beerman et al in 1957, incidences of skin metastasis from internal organs were found varying from 1 to $2.7 \%$. Willihad et al found 3 cases of skin metastases in a series of 430 autopsied cases of carcinoma. Carcinoma of the female breast is the most frequent source of cutaneous metastases. Gates found 25 cases of breast carcinoma in her series of 58 cases of skin metastases; Abrams et al. had 31 breast carcinomas in their series and Mehregan found 11 of 22 cases originating in the breast. In the review by Beerman, the sites of origin of cutaneous metastases are listed as breast- $50 \%$; stomach-I5 to $31 \%$; lung $12 \%$ : uterus- $9 \%$; kidney-9\%. Connor et al,4 in a series of 588 patients with surgically excised lesions metastatic to the skin on file at the AFIP, found the followingtobe the most frequent primary sites: breast-38\%; gastro-intestinal tract-- $17.4 \%$; lung-16.3\%: kidney-6.8\% [10].

The present study was concordant with the study by Hingway et al, which showed an association of malignancy of head and neck region with scalp metastasis, the follicular thyroid carcinoma being the commonest. ${ }^{1}$ In about $80 \%$ cases reported with thyroid carcinoma, $20 \%$ showed distant metastasis [11].
The incidence of cutaneous metastases from lung cancer varies from $2.8 \%-7.5 \%$ which holds an ominous prognosis [12]. In a retrospective study by Lookingbill et al. including 7316 cancer patients, skin involvement as a presenting sign was seen in only $0.8 \%$. Skin metastasis from lung malignancies are extremely rare and the prognosis in patients with cutaneous involvement is quite poor [13].

Out of the 35 cases of thymic tumors with extrathoracic metastases studied by T Vladislav et al, only 1 case had metastasis to the scalp [14]. Cutaneous metastases from Renal Cell Carcinoma occur at a late stage of the disease and bear a poor prognosis [15].

Skin metastases from colorectal adenocarcinoma commonly occur metachronously within the first two years after resection of the primary tumour and are often present simultaneously with metastases to other organs like the liver.

The most common primary sites of cutaneous colorectal metastasis have been reported as follows: rectum (55\%), sigmoid colon (17\%), transverse colon (9\%), rectosigmoid (7\%), cecum (4\%), and ascending colon (4\%) [16].

Carson HJ et al, performed a co relation study of histological and FNA biopsy which concluded that FNA was particularly effective in diagnosis of rapidly growing malignant tumors. Wide local excision of the cutaneous metastatic lesion is the preferred treatment option in isolated lesions which is quite rare. Multiple cutaneous metastases are only palliated due to dismal prognosis [5] Spitz DJ et al, demonstrated that FNA study would lead to a rapid and accurate diagnosis while evaluating scalp lesions [17]. A variety of inflammatory and neoplastic scalp lesions are encountered in surgical pathology. FNAC of scalp lesions is a rapid, easily accessible, safe, cost effective diagnostic modality. A good history would substantiate and help in arriving at the infrequent, yet right diagnosis [18].

\section{Conclusion}

Amongst the rare occurrence of scalp metastases, unfamiliar and exceptional cases were the metastases from thymic carcinoma and renal cell carcinoma. The aim of this study was to exhibit the vast variety of scalp lesions, with emphasis on the metastatic scalp lesions.

\section{What this study adds to the existing knowledge?}

Scalp lesions present a challenge for clinicians and radiologists, with similar appearances on radiologic images that may lead to diagnostic mistakes. This study exhibits the vast variety of scalp lesions, with emphasis on the metastatic scalp lesions. 


\section{Author's contribution}

Dr. Shreya Hegde: Conception, compilation, design of study and draft of article.

Dr. Vinitha Samartha: Data analysis and discussion.

Funding: No funding sources

Conflict of interest: None declared

Ethical Approval: This study was approved by the Institutional Ethics Committee

\section{References}

1. Morcillo Carratala R, Capilla Cabezuelo ME, Herrera Herrera I, Calvo Azabarte P, Dieguez Tapias S, Moreno de la Presa R, et al. Non traumatic lesions of scalp: Practical approach to imaging diagnosis: Neurologic/ Head and neck imaging. Radiograph. 2017;37(3):999-1000. doi: 10.1148/ rg. 2017160112.

2. Sariya D, Ruth K, Adams-McDonnell R, Cusack C, Xu $\mathrm{X}$, Elenitsas R, et al. Clinicopathologic correlation of cutaneous metastases. Arch Dermatol. 2007;143(5):613620. doi:10.1001/archderm.143.5.613.

3. Prodinger CM, Koller J, Laimer M. Scalp tumours. J German Soc Dermatol. 2018;16(6):730-753. doi: https:// doi.org/10.1111/ddg.13546.

4. Hingway SR, Poornima K. Cytodiagnosis of scalp lesions. J Med Sci Health. 2015;1(1):1-9.

5. Saikia B, Dey P, Saikia UN, Das A. Fine Needle Aspiration Cytology of Metastatic Scalp Nodules. Acta Cytologica. 2001;45(4):537-541.

6. Yu Q, Subedi S, Tong Y, Wei Q, Xu H, Wang Y, et al. Scalp metastases as first presentation of pulmonary adenocarcinoma. Onco TarTherapy. 2018;11:6147-6151. doi: https://doi.org/10.2147/OTT.S174577.

7. McSweeney W, Tan K. Cutaneous metastases as a presenting sign of metastatic NSCLC. J Surg Case Reports. 2019;10:1-4. doi: 10.1093/jscr/rjz279.

8. Ferraz VR, Vitorini-Araujo JL, Sementilli L, Neto JF, Veiga JCE. Lesion in Scalp and Skull as the First Manifestation of Hepatocellular Carcinoma. Case Rep Neurol Med. 2016;1-4. doi: 10.1155/2016/2897048.
9. El M'rabet FZ, Hottinger A, George AC, Tille JC, Castiglione-Gertsch M, Bodmer A. Cutaneous Metastasis of Endometrial Carcinoma: A Case Report and Literature Review. J Clin Gynecol Obstet 2012;1(1):19-23. doi: https:// doi.org/10.4021/jcgo6e.

10. Reingold IM. Cutaneous metastases from internal carcinoma. Cancer. 1966;19(2):162-168. doi: 10.1002/ 1097-0142(196602).

11. Mohan A, Kumar S, Kumar U.Atypical Presentation as Unilateral Renal and Soft Tissue Metastases from Follicular Carcinoma Thyroid. Int J Head Neck Surg. 2012;3(3):184186. doi: 10.5005/jp-journals-10001-1126.

12. Kamble R, Kumar L, Kochupalli V, Sharma A, Sandhoo MS, Mohanti BK. Cutaneous metastasis of lung cancer. Post Grad Med J 1995;71:741-743. doi: 10.1136/pgmj. 71. 842.741 .

13. Rachakonda KM, George MK, Peek RD. Scalp metastases - an unusual Presentation of non-small cell lung cancer prognosis of cutaneous metastases in the current era. J Cancer Res Therapeut.2013;9(1):145-147. doi:10. 4103/0973-1482.110375.

14. Vladislav T, Jain RK, Alvarez R, Mehta RJ, GökmenPolar Y, Kesler KA, et al. Extrathoracic metastases of thymic origin:a review of 35 cases. Modern Pathol. 2012; 25(3):370-377. doi: 10.1038/modpathol.2011.178.

15. Sountoulides P, Metaxa L, Cindolo L. Atypical presentations and rare metastatic sites of renal cell carcinoma: a review of case reports. J Med Case Rep. 2011; 5(1):429-438. doi: https://doi.org/10.1186/1752-1947-5429.

16. Amarjyothi JMV, Villalan R, Jeyasudhahar J, Naganath Babu et al. Interesting Case of Skin Metastasis in Colorectal Cancer and Review of Literature. Case Rep Surg. 2018;18. doi: https://doi.org/10.1155/2018/7102845.

17. Spitz DJ, Reddy V, Selvaggi SM, Kluskens L, Green L, GattusoP. Fine needle aspiration of scalp lesions. Diagnos Cytopathol. 2000;23(1):35-38.

18. Saikia B, Dey P, Saikia UN, Das A. Fine Needle Aspiration Cytology of Metastatic Scalp Nodules. Acta Cytologica. 2001;45(4):537-541. doi:10.1159/000327861.

\section{How to cite this article?}

Hegde S, Samartha V. Potpourri of interesting scalp lesions. Trop J Path Micro 2019;5(11):948-953.doi:10.17511/ jopm.2019.i11.18 